Hamstring Injury Prevention in Soccer: Before or After Training?

Dr Ric Lovell1, Mr Michael Knox, Dr Matthew Weston², Dr Jason C. Siegler ${ }^{1}$, Mr Scott Brennan ${ }^{1}$, Dr Paul W. M. Marshall ${ }^{1}$

${ }^{1}$ School of Science and Health, Western Sydney University, Australia ${ }^{2}$ School of Social Sciences, Business \& Law, Teesside University, Middlesbrough, United Kingdom

Running Head: Hamstring Injury Prevention Scheduling

Corresponding Author:

Dr. Ric Lovell

School of Science and Health

Western Sydney University

Locked Bag 1797

Penrith, NSW 2751, AUSTRALIA

Phone: +61 (0)2 46203304

Fax: +61 (0)2 46203020

E-mail: r.lovell@westernsydney.edu.au

Word Count: 4122

Tables: 3

Figures: 3 


\title{
Hamstring Injury Prevention in Soccer: Before or After Training?
}

\begin{abstract}
We examined the effects of a 12-week program of Nordic hamstring exercises (NHE), administered before or after football training, upon eccentric hamstring strength, muscle activity, and architectural adaptations. Amateur soccer players were randomized into 3 groups. The control group (CON; $n=11)$ undertook core stability exercises, whereas a periodized NHE program was delivered either before (NHEBEF; $n=10$ ) or after (NHEAFT; $n=14$ ) bi-weekly training sessions. Outcome measures included peak torque and concomitant normalized peak surface electromyography signals (sEMG) of the biceps femoris $(\mathrm{BF})$ and medial hamstring $(\mathrm{MH})$ muscles during knee flexor maximal eccentric contractions, performed at $30^{\circ} \cdot \mathrm{s}^{-1}$. Ultrasonography was used to determine $\mathrm{BF}$ muscle thickness, muscle fiber pennation angle, and fascicle length. Performing the NHE derived likely moderate peak torque increases in both $\mathrm{NHE}_{\mathrm{BEF}}(+11.9 \% ; 90 \%$ confidence interval: $3.6 \%$ to $20.9 \%)$ and $\mathrm{NHE}_{\text {AFT }}$ $(+11.6 \% ; 2.6 \%$ to $21.5 \%)$ versus CON. Maximum sEMG increases were moderately greater in the BF of both NHE training groups versus CON. There were likely moderate increases in BF muscle thickness $(+0.17 \mathrm{~cm} ; 0.05 \mathrm{~cm}$ to $0.29 \mathrm{~cm}$ ) and likely small pennation angle increases $\left(+1.03^{\circ} ;-0.08^{\circ}\right.$ to $\left.2.14^{\circ}\right)$ in NHEAFT versus CON and NHEBEF. BF fascicle length increases were likely greater in NHE $\mathrm{NEF}_{\text {BEF }}(+1.58 \mathrm{~cm} ; 0.48 \mathrm{~cm}$ to $2.68 \mathrm{~cm}$; small effect) versus CON and $\mathrm{NHE}_{\mathrm{AFT}}$. A 12-week eccentric hamstring-strengthening program increased strength and SEMG to a similar magnitude irrespective of its scheduling relative to the football training session. However, architectural adaptations to support the strength gains differed according to the timing of the injury prevention program.
\end{abstract}

Keywords: injury prevention, scheduling, hamstring, adaptation, soccer 


\section{Introduction}

Hamstring strain injury (HSI) is the most prevalent injury in both amateur (van Beijsterveldt et al., 2015) and professional (Ekstrand et al., 2011; Hawkins et al., 2001) soccer players, and its incidence has continued to rise (Ekstrand et al., 2016). Prospective studies have identified modifiable HSI risk factors such as eccentric knee flexor weakness (Opar et al., 2015; Timmins, Bourne, et al., 2015) and muscle architecture characteristics (Timmins, Bourne, et al., 2015) (e.g. biceps femoris fascicle length) as a focus for HSI injury prevention programs. At present it is thought that the most pragmatic exercise choice for HSI injury prevention that addresses both eccentric knee flexor strength and muscle architecture is the Nordic hamstring exercise (NHE). The NHE is wellknown in elite soccer, with $88 \%$ of European teams familiar with the exercise (Bahr et al., 2015), and it was ranked in the top five injury prevention exercises by practitioners (McCall et al., 2014).

Chronic NHE programs have been shown to reduce hamstring injuries by 57 $72 \%$ in both amateur and professional soccer players (Arnason et al., 2008; Mjølsnes et al., 2004; Petersen et al., 2011) likely mediated by NHE induced eccentric hamstring strength gains (Iga et al., 2012; Mjølsnes et al., 2004; Small et al., 2009) and favorable increases in fascicle length of the biceps femoris long head (Bourne et al., 2016; Timmins, Ruddy, et al., 2015). The $\mathrm{NHE}$ is also prescribed in the FIFA11+ injury prevention program, an international scheme designed to reduce injuries in the estimated 300 million+ players participating in soccer at the amateur or recreational level (Bizzini et al., 2013), and whose HSI incidence during training sessions is higher compared with professional players (van Beijsterveldt et al., 2015).

Despite the reach and evidence base supporting the NHE (Arnason et al., 2008; Mjølsnes et al., 2004; Petersen et al., 2011), there is no consensus regarding its scheduling in relation to field-training sessions, with studies administering the NHE before (Iga et al., 2012; Small et al., 2009), sometime during (Arnason et al., 2008; Petersen et al., 2011), or after football training (Small et al., 2009; van der Horst et al., 2015). To date, just one study has examined chronic strength changes and fatigability following a 12-week NHE program delivered either before (NHEBEF) or after (NHEAFT) soccer training (Small et al., 2009). The scheduling of the NHE program influenced the eccentric hamstring fatigue profile during simulated soccer matches, in which the NHEAFT group demonstrated a reduced loss of eccentric strength at the end of each half. However, the adaptive response was not reported in this study and further work is warranted to explore the underlying mechanisms of eccentric hamstring strength gains, and whether these were dependent upon the scheduling of NHE's relative to soccer training sessions.

The adaptive response to eccentric strength training is multifactorial, and may include increases in motor unit discharge rate (Higbie et al., 1996) and alterations in muscle architecture such as hypertrophy (Bourne et al., 2016; Franchi et al., 2014) and fascicle lengthening (Bourne et al., 2016; Timmins, Ruddy, et al., 2015). Hypertrophic signaling is governed by mechanical tension and intramuscular metabolic stress (Douglas et al., 2016), the degree 
of which may be influenced by the muscle status at either the beginning or end of football activity. However, the concurrent training literature is somewhat equivocal at present, for example, research has identified that resistance exercise following high-intensity interval training provides a greater anabolic stimulus (Fyfe et al., 2016) and exacerbates hypertrophy following aerobic training (Lundberg et al., 2013), versus resistance training performed in isolation. In contrast, other data suggests that the fatigue (Lovell et al., 2016; Marshall et al., 2014) and glycogen depletion (Krustrup et al., 2006) inherent to soccer activity may negatively impact anabolic signaling responses to subsequent strength training (Creer et al., 2005). Hence, the adaptive stimulus following strengthening exercises scheduled before or after soccer training is complex and further understanding of the adaptive responses according to the scheduling of injury prevention exercises would inform industry practice.

Therefore, the aim of the current study was to examine the eccentric strength, neural activation, and muscle architecture adaptations of the biceps femoris to a 12-week program of NHE's performed either before or after bi-weekly soccer training in amateur players. We hypothesized that irrespective of scheduling, the NHE program would increase eccentric hamstring strength but that the mechanisms of adaptation may differ according to the timing of the injury prevention program.

\section{Materials and Methods}

\section{Participants}

Seventy-two amateur male soccer players were invited to participate in the trial, which was approved by Western Sydney Universities Human Research and Ethics Committee (H9840). The invitee's represented a convenience sample drawn from five teams who participated recreationally in a league situated locally to the University. This cohort was chosen due to the fact that NHE intervention was implemented as part of the FIFA 11+ injury prevention program to reduce hamstring muscle strain injuries for amateur players whom may not have access to the necessary equipment and/or the expertise required for eccentric strength training of the hamstring muscle groups (Junge et al., 2011). Players routinely competed in one competitive 90-min match every week, and each team hosted bi-weekly field-training sessions during the season. The study was conducted during the in-season phase of competition, between the Australian winter months of June-August. Of the 72 players who attended study information briefings, 42 accepted and provided both written and verbal informed consent (Age: $23.6 \pm 4.7$ years; stature: $178.1 \pm 5.9 \mathrm{~cm}$; weight: $77.4 \pm 11.4 \mathrm{~kg}$ ). Players' that enrolled in the study were free from any musculoskeletal injury and had been so for the preceding 6 months.

\section{Experimental design}

Players were randomly allocated into three groups (Fig. 1), two of which were experimental groups, and the other acted as a control (CON), but all players 
were masked to the study aims. Randomization was performed within each squad, to guard against the teams' specific training practices influencing the effects upon outcome measures. The two experimental groups undertook a 12-week program of Nordic Hamstring Exercises (NHE; see Hamstring Injury Prevention Program), which was administered by trained research assistants either before ( $\mathrm{NHE}_{\mathrm{BEF}}$ ), or after (NHE $\mathrm{NFT}_{\mathrm{AF}}$ ) bi-weekly field training sessions. To attenuate contamination effects, CON players were prescribed an exercise regime that was not expected to alter the outcome measures adopted. Following familiarization, players' attended a baseline laboratory assessment, during which their eccentric hamstring strength and corresponding muscle activity were determined, together with hamstring muscle architecture (see Outcome Measures). Players returned to the laboratory in the week following the conclusion of program. Baseline and follow-up laboratory assessments were performed $48 \mathrm{~h}$ post training and/or matches and were scheduled at the same time of day.

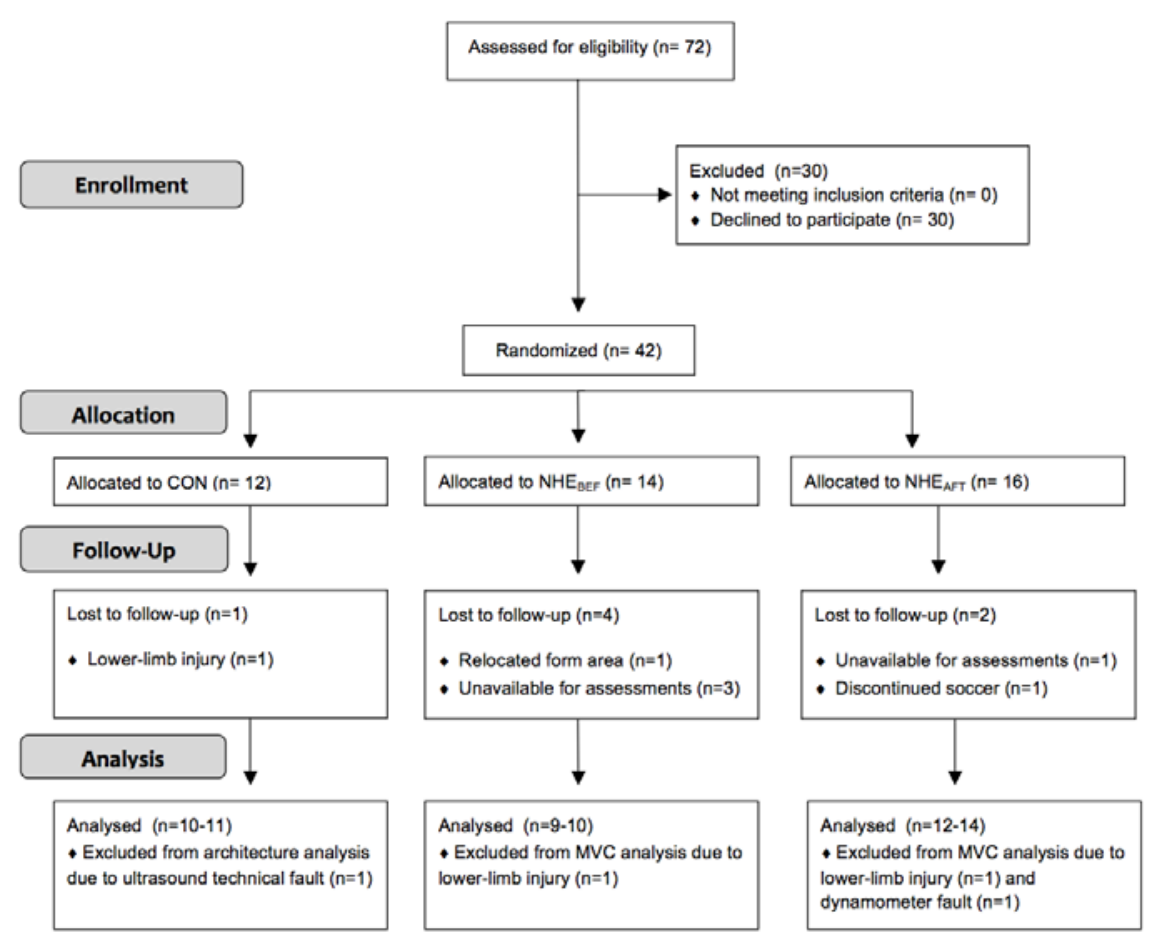

Figure 1: Consolidated Standards of Reporting Trials (CONSORT) flow diagram.

Hamstring Injury Prevention Program

Experimental groups undertook the 12-week NHE intervention program, outlined in Table 1. The total volume of NHE repetitions administered was based upon existing research (Mjølsnes et al., 2004; Petersen et al., 2011). NHEBEF was administered after the warm-up of each field-session, and players in NHEAFT performed the routine at the end of training. The CON group performed core stability exercises shown to have little effect on hamstring muscle activity (static bench and sideways bench; Ekstrom et al., 
2007), which were prescribed and periodized according to the FIFA 11+ routine (see table 1), and delivered before or after training on alternative training sessions to mask the study aims.

Outcome Measures

Biceps femoris muscle architecture was assessed via two-dimensional Bmode ultrasonography (Echo Blaster 128; Telemed, Vilnius, Lithuania), by collecting a sagittal view of the biceps femoris whilst players lay prone with the knee of their dominant leg fully extended. A $10 \mathrm{MHz}$ linear-array transducer $(60 \mathrm{~mm}$ width, $60 \mathrm{~mm}$ depth) was applied according to the procedures described in previous studies of BF architecture (Timmins, Ruddy, et al., 2015; Timmins, Shield, et al., 2015). Muscle thickness (MT) and pennation angle (PA) were determined as outlined in figure 2. Fascicle length (FL) was estimated using a validated equation (Kellis et al., 2009).

Three images were collected at baseline and follow-up laboratory assessments, and were analysed off-line (Echo Wave II v2.3.6, Telemed, Vilnius, Lithuania). Average values were used to determine muscle thickness, pennation angle and estimated fascicle length. Between-day, within-subject coefficients of variation (\%) for MT, PA, and FL were determined in our laboratory a priori as $3.3(90 \% \mathrm{Cl}: 2.5-5.2 \%), 4.2(90 \% \mathrm{Cl}: 3.1-6.6 \%)$, and $8.7 \%$ (90\% Cl: 6.4-13.8\%), respectively.

Table 1: Periodization of the NHE intervention and the static bench and sideways static bench exercises prescribed to CON.

\begin{tabular}{ccccc}
\hline Week & $\begin{array}{c}\text { Session } \\
\text { Frequency }\end{array}$ & Sets & Repetitions & $\begin{array}{l}\text { Weekly } \\
\text { Volume }\end{array}$ \\
\hline
\end{tabular}

Nordic hamstring exercise

$\begin{array}{ccccc}1 & 1 & 2 & 5 & 10 \\ 2 & 2 & 3 & 5 & 30 \\ 3 & 2 & 3 & 6 & 36 \\ 4 & 2 & 4 & 6 & 48 \\ 5 & 2 & 4 & 7 & 56 \\ 6 & 2 & 7 & 56 \\ 7 & 2 & 4 & 8 & 64 \\ 8 & 2 & 4 & 8 & 64 \\ 9 & 2 & 4 & 9 & 72 \\ 10 & 2 & 4 & 9 & 72 \\ 11 & 2 & 4 & 10 & 80 \\ 12 & 2 & 4 & 12 & 96\end{array}$

Static bench and sideways static bench exercises

\begin{tabular}{ccccc}
1 & 1 & 3 & $20 \mathrm{~s}$ & $60 \mathrm{~s}$ \\
2 to 4 & 2 & 3 & $25 \mathrm{~s}$ & $150 \mathrm{~s}$ \\
5 to 7 & 2 & 3 & $30 \mathrm{~s}$ & $180 \mathrm{~s}$ \\
8 to 12 & 2 & 3 & $40 \mathrm{~s}$ & $240 \mathrm{~s}$ \\
\hline
\end{tabular}




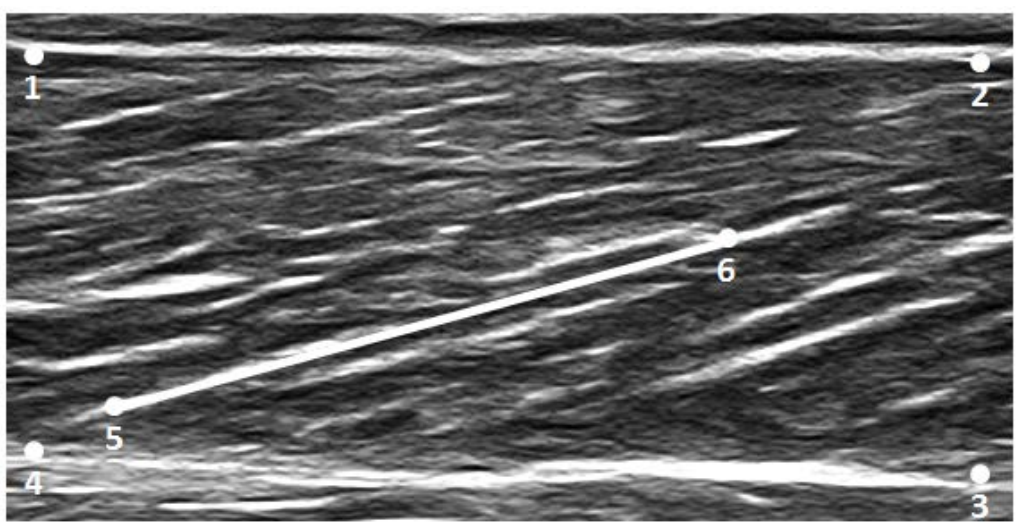

Figure 2: An ultrasound image of the biceps femoris. The lines between points 1-2, and 3-4 represent superficial and deep aponeurosis, respectively. Pennation Angle was determined as the line of best fit placed along three fascicles relative to the deep aponeurosis (example represented as the line between points 5-6).

Eccentric hamstring strength was determined from gravity-corrected torque signals collected during $30^{\circ} \cdot \mathrm{s}^{-1}$ maximal voluntary contractions (MVC) of the knee flexors using an isokinetic dynamometer (Chattanooga, Kin-Com 125 Version 5.32). The dynamometer was configured so that the participant performed MVC's in a prone position, with the cuff applied $2 \mathrm{~cm}$ superior to the lateral malleolus and the pivot arm aligned to the lateral femoral epicondyle. Gravity-corrected torque signals were recorded using a strain gauge located in the lever arm of the dynamometer, the position (angle) of which was also determined from $90^{\circ}$ knee flexion to full extension $\left(0^{\circ}\right.$ knee flexion angle). Extraneous movement was restrained using straps applied above and beneath the gluteal muscles. Following a standard warm-up, players performed 3 maximal contractions of their dominant limb, interspersed by 60 s of passive rest. Participants were instructed to contract their hamstrings "as forcefully as possible" throughout the full range of motion, with verbal encouragement provided by two investigators throughout. Our laboratories between-day, within-subject coefficient of variation for eccentric hamstring peak torque is $7.1 \%(90 \% \mathrm{Cl}: 5.2-11.2 \%)$.

Surface electromyographic (sEMG) signals were recorded during each MVC using pairs of $\mathrm{AG} / \mathrm{AgCl}$ surface electrodes $(10 \mathrm{~mm}$ diameter, $10 \mathrm{~mm}$ interelectrode distance) applied to the bicep femoris (BF) and medial hamstring (MH; semitendinosus and semimembranosus) muscles, placed according to previous recommendations (Rainoldi et al., 2004).

Torque, position, and sEMG signals were collected at $2000 \mathrm{~Hz}$ using an analog to digital converter (Powerlab 16/35, ADI instruments, Australia; 16-bit analog to digital conversion). sEMG was amplified (ML138 Octal Bio Amp, ADI instruments, Australia), band pass filtered (between 10 and $500 \mathrm{~Hz}$ ), and subsequently rectified and smoothed using a root mean square (RMS) calculation with a $200 \mathrm{~ms}$ sliding window to determine the amplitude (mV). Maximal torque was defined as the highest value recorded during three MVC's. Average torque was also determined for each $15^{\circ}$ excursion of the 
MVC. Peak sEMG data was normalised ( $\mathrm{EEMG}$ ) according to the peak EMG amplitudes determined in each $15^{\circ}$ epoch during the baseline MVCs.

Statistics

Prior to analysis, pre-post trial change scores were log-transformed to attenuate any bias due to non-uniformity error. Comparison of treatment effects was performed using ANCOVA (IBM SPSS version 22.0, Armonk, NY), with baseline measures of each outcome variable imputed, together with program compliance as covariates to account for any between-group imbalances. Compliance for $\mathrm{NHE}_{\mathrm{BEF}}$ and $\mathrm{NHE}_{\mathrm{AFT}}$ was coded as the percentage of repetitions completed in reference to the total prescribed volumes presented in table 1 . As we did not expect the core stability exercises undertaken by the control group to influence outcome measures, compliance for this group was imputed as $0 \%$ in the model. Backtransformed effect estimates were examined with magnitude-based inferences calculated via customized spreadsheets (Hopkins, 2007), using $90 \%$ confidence intervals to express the uncertainty of the estimates. Effect magnitudes were assessed using standardized thresholds for small (0.2), moderate (0.6), and large (1.2) changes derived from the between-subject standard deviations of baseline measures from the control group. Inferences were determined according to the disposition of the confidence interval for the mean difference to the standardized thresholds. Mechanistic inferences in outcome measures were qualified as likely (75-95\%), very-likely (95-99.5\%) or most-likely (>99.5\%), but classified as unclear where the confidence intervals overlapped both positive and negative thresholds by $5 \%$ (Batterham and Hopkins, 2006). Data are reported as estimated marginal means (adjusted by baseline values and compliance) $\pm 90 \%$ confidence intervals.

\section{Results}

\section{Compliance}

Compliance to the NHE program was likely greater (small effect) in the NHE $A$ AFT training group (Mean: $46.8 \% ; 40.8 \%$ to $52.8 \%$ ) versus NHE $34.7 \% ; 28.1 \%$ to $41.4 \%$ ). The control group undertook $47.5 \%$ (Range: $26.0 \%$ to $60.0 \%$ ) of the core stability program used to mask the study aims.

\section{Peak Torque}

Changes in eccentric hamstring peak torque were greater in both $\mathrm{NHE}$ BEF $(+11.9 \% ; 3.6 \%$ to $20.9 \%)$ and $\mathrm{NHE}_{\mathrm{AFT}}(+11.6 \% ; 2.6 \%$ to $21.5 \%)$ versus control (likely moderate effect), with no difference denoted between NHEBEF and NHE $\mathrm{AFT}_{\text {. The }}$ There no changes (CON: $\Delta-1.4 \pm 6.5^{\circ}$; NHE $\mathrm{NHEF}: \Delta-1.5 \pm$ $7.0^{\circ}$; NHE AFT: $\Delta .5 \pm 6.0^{\circ}$ knee flexion) or between group differences in the angle that peak torque was observed (10.2 $\pm 10.8^{\circ}$ knee flexion). 
Likely to very-likely small increases in average torque changes were observed in both $\mathrm{NHE}_{\mathrm{BEF}}(\Delta 13.3 \% ; 8.2 \%$ to $18.6 \%)$ and $\mathrm{NHE}_{\text {AFT }}(\Delta 20.9 \% ; 14.7 \%$ to $27.5 \%$ ) versus control ( $\Delta-0.7 \%$; $-6.4 \%$ to $5.3 \%$ ), with no difference between the NHE groups.

The average torque changes in each $15^{\circ}$ segment of knee flexion angle are presented in figure 3 . At long hamstring muscle lengths $\left(0-30^{\circ}\right.$ knee flexion), both NHE training groups increased average eccentric torque versus CON (likely small-moderate effects). NHEAFT had greater changes in average torque versus $\mathrm{CON}$ in the mid-range of the isokinetic contraction $\left(30-60^{\circ}\right.$ knee flexion; likely moderate effects), and versus both CON and NHEBEF groups at short lengths (60-90 knee flexion; likely small-moderate effects).

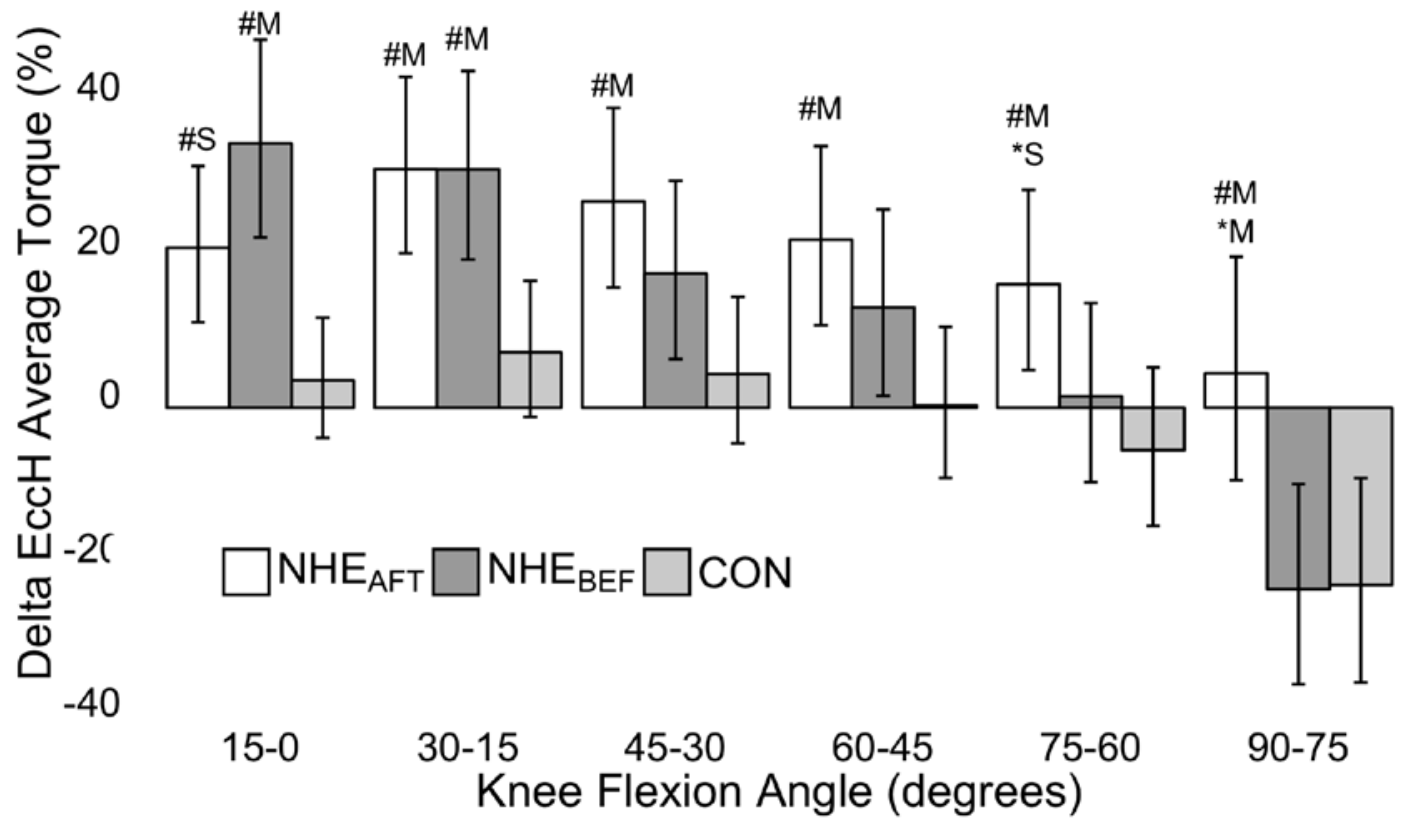

Figure 3: Changes in eccentric hamstring average torque between training groups in $15^{\circ}$ ranges of knee flexion. \# denotes greater vs. CON; * denotes greater vs. $\mathrm{NHE}_{\mathrm{BEF}} . \quad \mathrm{S}=$ small effect size; $\mathrm{M}=$ medium effect size. Error bars represent $90 \%$ confidence intervals.

\section{Surface Electromyography}

Normalised BF sEMG changes were greater in both NHE intervention groups versus CON (likely moderate effects), with a greater change in NHEBEF vs $\mathrm{NHE}_{\text {AFT }}$ (likely small effect). The greater increases in NHE only between $0-30^{\circ}$ of knee flexion (see table 2). Increases in nEMG recorded in the $\mathrm{MH}$ were higher in NHE $\mathrm{BEF}_{\text {a }}$ and NHEAFT versus CON (likely small effects) at shorter muscle lengths (45-90 knee flexion; likely smallmoderate effects), with no difference between the NHE groups. 
Table 2: Delta (\%) maximal sEMG recorded in the Biceps Femoris (BF) and Medial Hamstrings $(\mathrm{MH})$ according to knee flexion angle during maximal eccentric knee extension at $30^{\circ} \cdot \mathrm{s}^{-1}$.

\begin{tabular}{|c|c|c|c|}
\hline \multirow{2}{*}{$\begin{array}{l}\text { Knee Flexion Angle } \\
\left({ }^{\circ}\right)\end{array}$} & \multicolumn{3}{|c|}{ Experimental Group } \\
\hline & $\mathrm{NHE}_{\mathrm{AFT}}$ & $\mathrm{NHE}_{\mathrm{BEF}}$ & CON \\
\hline \multicolumn{4}{|l|}{ BF Max EMG } \\
\hline $\begin{array}{l}15-0 \\
30-15 \\
45-30 \\
60-45 \\
75-60 \\
90-75\end{array}$ & $\begin{array}{l}48.6(19.6-77.6)^{\# \mathrm{M}} \\
47.2(18.2-76.2)^{\# \mathrm{M}} \\
63.0(34.0-92.1)^{\# \mathrm{M}} \\
62.0(33.0-91.0)^{\# \mathrm{M}} \\
61.2(32.2-90.2)^{\# \mathrm{M}} \\
68.3(39.3-97.3)^{\# \mathrm{M}}\end{array}$ & $\begin{array}{c}76.8(47.1-106.4)^{\# \mathrm{M} \wedge \mathrm{S}} \\
79.1(49.5-108.8)^{\# \mathrm{M} \wedge} \mathrm{S} \\
69.3(39.7-99.0)^{\# \mathrm{M}} \\
86.4(56.8-116.1)^{\# \mathrm{M}} \\
78.7(49.1-108.4)^{\# \mathrm{M}} \\
69.5(39.8-99.1)^{\# \mathrm{M}}\end{array}$ & $\begin{array}{c}-29.3(-60.1-1.5) \\
-20.2(-51.0-10.6) \\
-29.3(-60.1-1.5) \\
-24.1(-54.9-6.7) \\
-28.8(-59.6-2.0) \\
-36.1(-66.9--5.3)\end{array}$ \\
\hline \multicolumn{4}{|l|}{ MH Max EMG } \\
\hline $\begin{array}{l}15-0 \\
30-15 \\
45-30 \\
60-45 \\
75-60 \\
90-75\end{array}$ & $\begin{array}{c}34.9(1.4-68.3) \\
37.0(3.6-70.5) \\
41.7(8.2-75.1) \\
55.2(21.8-88.7)^{\# S} \\
46.9(13.5-80.4)^{\# \mathrm{~S}} \\
52.6(19.1-86.0)^{\# \mathrm{M}}\end{array}$ & $\begin{array}{c}37.4(4.8-70.1) \\
31.5(-1.2-64.1) \\
30.9(-1.7-63.6) \\
26.8(-5.9-59.4) \\
43.4(10.7-76.0)^{\# S} \\
47.8(15.1-80.4)^{\# \mathrm{M}}\end{array}$ & $\begin{array}{c}36.3(2.6-70.0) \\
33.7(0.0-67.4) \\
33.9(0.2-67.6) \\
13.9(-19.8-47.6) \\
0.5(-33.2-34.2) \\
-18.2(-51.9-15.4)\end{array}$ \\
\hline $\begin{array}{l}\text { \# denotes grea } \\
\text { small effect size }\end{array}$ & $\begin{array}{l}\mathrm{V} ;{ }^{*} \text { denotes greate } \\
\text { lium effect size. Da }\end{array}$ & NHE $E_{B E F} ;^{\wedge}$ denotes & $\begin{array}{l}\text { ater vs. NHE }{ }_{A F T} \text { S } \\
\text { arginal means } \pm 90^{\circ}\end{array}$ \\
\hline
\end{tabular}

\section{Biceps Femoris Muscle Architecture}

Muscle thickness and fascicle angle of pennation increased in the NHEAFT training group versus both $\mathrm{NHE}_{\mathrm{BEF}}$ and $\mathrm{CON}$, whereas the estimated change in biceps femoris fascicle length (expressed in both absolute, and relative to muscle thickness terms) was higher in NHE $\mathrm{BEF}_{\mathrm{BE}}$ versus both $\mathrm{NHE}_{\mathrm{AFT}}$ and CON (see table 3).

Table 3: Changes in muscle architecture following the trial.

\begin{tabular}{|c|c|c|c|}
\hline Characteristic & Group & Mean Change & $\begin{array}{c}90 \% \text { Confidence } \\
\text { Interval }\end{array}$ \\
\hline Muscle Thickness (cm) & $\begin{array}{l}\mathrm{NHE}_{\mathrm{AFT}} \\
\mathrm{NHE}_{\mathrm{BEF}} \\
\mathrm{CON}\end{array}$ & $\begin{array}{l}0.17^{\# \mathrm{M}{ }^{*} \mathrm{M}} \\
-0.07 \\
-0.19\end{array}$ & $\begin{array}{c}0.05 \text { to } 0.29 \\
-0.17 \text { to } 0.03 \\
-0.34 \text { to }-0.03\end{array}$ \\
\hline Pennation Angle $\left({ }^{\circ}\right)$ & $\begin{array}{l}\mathrm{NHE}_{\mathrm{AFT}} \\
\mathrm{NHE} \mathrm{E}_{\mathrm{BEF}} \\
\mathrm{CON}\end{array}$ & 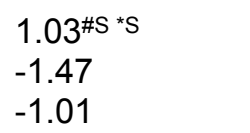 & $\begin{array}{l}-0.08 \text { to } 2.14 \\
-2.37 \text { to }-0.58 \\
-2.43 \text { to } 0.42\end{array}$ \\
\hline Fascicle Length $(\mathrm{cm})$ & $\begin{array}{l}\mathrm{NHE}_{\mathrm{AFT}} \\
\mathrm{NHE}_{\mathrm{BEF}} \\
\mathrm{CON}\end{array}$ & $\begin{array}{l}-0.29 \\
1.58^{\# S^{\wedge S}} \\
-0.67\end{array}$ & $\begin{array}{c}-1.70 \text { to } 1.11 \\
0.48 \text { to } 2.68 \\
-2.45 \text { to } 1.11\end{array}$ \\
\hline FL:MT (cm) & $\begin{array}{l}\mathrm{NHE}_{\mathrm{AFT}} \\
\text { NHE } \mathrm{B}_{\mathrm{BEF}} \\
\mathrm{CON}\end{array}$ & $\begin{array}{l}-0.32 \\
0.76^{\# S \wedge S} \\
-0.06\end{array}$ & $\begin{array}{c}-0.90 \text { to } 0.27 \\
0.30 \text { to } 1.21 \\
-0.80 \text { to } 0.68\end{array}$ \\
\hline
\end{tabular}

\# denotes greater vs. $\mathrm{CON} ;{ }^{*}$ denotes greater vs. $\mathrm{NHE}_{\mathrm{BEF}} ;{ }^{\wedge}$ denotes greater vs. NHEAFT; $\mathrm{S}=$ small effect size; $M$ = medium effect size. 


\section{Discussion}

The aim of this study was to compare the training impact of a Nordic Hamstring injury prevention program administered before or after regular football training sessions. Despite relatively modest compliance to the program in both training groups, we observed the following: 1) peak eccentric knee flexor torque was enhanced by the NHE program, regardless of its scheduling; 2) performing the NHE also increased eccentric hamstring strength in the extended joint position associated with the most common hamstring strain injury mechanism; 3 ) biceps femoris muscle activation during maximal eccentric contractions was increased across the range of motion for both NHE groups; and 4) bicep femoris muscle thickness and pennation angle were only increased following $\mathrm{NHE}_{\mathrm{AFT}}$, yet bicep femoris fascicle length was increased exclusively in NHEBEF.

The peak eccentric hamstring strength gains observed here were similar between the $\mathrm{NHE}_{\mathrm{BEF}}$ and $\mathrm{NHE}_{\mathrm{AFT}}(\sim 12 \%)$, when adjusted for program compliance and baseline eccentric hamstring strength, and were of a similar magnitude to those previously reported (11-21\%; Mjølsnes et al., 2004; Iga et al., 2012). We have extended previous findings by the observed $22-31 \%$ increase in average torque applied between $0-30^{\circ}$ of knee flexion (elongated hamstring muscle length) following the NHE program, irrespective of scheduling. This is an important observation because the proposed mechanism of HSI injury (Guex and Millet, 2013) suggests that specific emphasis should be placed upon strengthening of the muscles in a lengthened position, rather than peak torque per se. Previous studies have inferred a rightward shift in the knee flexor torque-joint angle relationship from measurement of angle of peak torque as evidence of strengthening in a lengthened muscle position (Brughelli et al., 2010; Clark et al., 2005) However angle of peak torque suffers from a high degree of variability (Iga et al., 2012) and, as observed in this study, is a measure that may not be sensitive enough to detect real changes in torque development throughout the range of motion.

To our knowledge, a novel finding of this study was the divergent mechanisms underpinning the strength gains achieved following the NHE programs. Both NHE training groups had increased neural activity of the biceps femoris during maximal hamstring eccentric contractions versus controls, a classic adaptation to strength training (Higbie et al., 1996). However, strength adaptation in the NHEBEF group was characterized only by an increased BF fascicle lengthening, whereas the NHEAFT cohort demonstrated the typical hypertrophic response, identified by an increased muscle thickness and pennation angle. Increases in muscle thickness and pennation angle in NHE $_{\text {AFT }}$ were congruent with previous research (Timmins, Ruddy, et al., 2015), and is considered to represent an increase of myofibrils in parallel, enabling the greater transmission of force developed through the musculotendon unit (Blazevich et al., 2007). The scheduling-specific response observed in this study is consistent with the notion that hypertrophic signaling is governed by mechanical tension and metabolic stress (Douglas et al., 2016), given the major metabolic changes (Krustrup et al., 2006) induced by 
football activity, coupled with its fatiguing nature (Lovell et al., 2016; Marshall et al., 2014). Performing resistance training following high-intensity intervaland endurance-training has also been shown to augment anabolic signaling pathways (Fyfe et al., 2016) and hypertrophy (Lundberg et al., 2013).

Despite the absence of muscle morphology adaptations observed when performing the NHE prior to football-training, peak torque improvements were equivalent to $\mathrm{NHE}_{\mathrm{AFT}}$, and moreover, strength gains at elongated muscle lengths associated with the $\mathrm{HSI}$ mechanism were of a greater magnitude. This may be explained by the increased fascicle length that was exclusive to $\mathrm{NHE}_{\mathrm{BEF}}$, the magnitude of which (12.9\%) exceeded the minimum detectable change thresholds previously reported (Timmins, Shield, et al., 2015) but was slightly less than that achieved in laboratory eccentric strengthening studies ( 16-21\%; Timmins, Ruddy, et al., 2015; Bourne et al., 2016) which attained far greater training compliance (91-99.5\%). An increased fascicle length is considered to reflect a greater number of sarcomeres in-series, facilitating a rightward shift in the knee flexor torque-angle relationship (Blazevich et al., 2007), evident here by the concomitant greater eccentric strength gains and muscle activity increases at extended joint positions with NHE $\mathrm{BEF}_{\text {. Th }}$ enhanced capacity to tolerate stretch and generate torque is suggested to reduce sarcomere strain and mechanical disruption (Morgan, 1990), potentially diminishing microscopic trauma caused by intermittent highintensity exercise (Magalhães et al., 2010), and rendering the muscle less susceptible to strain injury (Timmins, Bourne, et al., 2015). It is unclear why

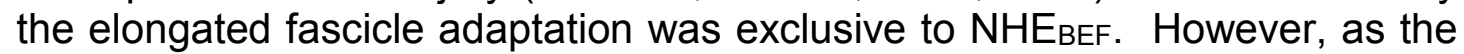
training range of motion has been proposed as the dominant stimulus for fascicle length increases (Blazevich et al., 2007), we cannot discount that preforming the $\mathrm{NHE}$ in a non-fatigued state before football training, may result in a greater stretch stimulus. Further work is certainly warranted to confirm or refute our divergent muscle adaptations according to exercise scheduling.

In our study, compliance to the NHE program was modest $(\sim 41 \%$ of prescribed volume), which has also been a feature of NHE intervention programs administered both in elite (Bahr et al., 2015) and community (Gabbe et al., 2006) settings. Low implementation maybe due to the fatiguing nature of the NHE (Lovell et al., 2016; Marshall et al., 2015), or the degree of soreness that eccentric training exercises such as the NHE can elicit (Brockett et al., 2001; Gabbe et al., 2006). In our study in amateur players, training sessions were often cancelled due to bad-weather, and players were often missing or late for training due to work or family commitments. We observed a $12 \%$ higher compliance when the NHE intervention program was scheduled at the end of training. Players and research assistants informally reported that when the participants arrived late due to other commitments, both the players and their coaches preferred them to immediately join squad-based field training, rather than perform the NHE program. Whilst we acknowledge that this evidence for scheduling related compliance is weak, it may be worthy of both further research and consideration by injury prevention policy makers.

As identified in this study, the optimal time to schedule injury prevention exercise (such as the NHE) in relation to football training remains equivocal, 
and is complicated by the myriad of factors that inform exercise prescription. Whilst peak and average eccentric hamstring strength gains were similar when the NHE was administered either before or after training, a greater magnitude of improvement was observed in NHE $\mathrm{BEF}_{\text {at }}$ axtended muscle lengths. Increased torque at extended muscle lengths may be associated with the fascicle length increase only observed in NHE $\mathrm{BEF}_{\mathrm{BEF}}$. These combined findings suggest the scheduling of $\mathrm{NHE}_{\mathrm{BEF}}$ may have more relevance to injury prevention given the proposed injury mechanism (Guex and Millet, 2013). In the extended joint position, $\mathrm{NHE}_{\mathrm{BEF}}$ strength gains were accompanied by greater increases in biceps femoris sEMG, an adaptation that may be particularly relevant to players with prior hamstring strain injury, whose neuromuscular control is considered to be impaired (Sole et al., 2011). Alternatively, performing a volume of NHE repetitions akin to those prescribed in both the current and previous (Mjølsnes et al., 2004; Petersen et al., 2011; Van der Horst et al., 2015) training studies prior to football training has been shown to induce greater reductions in hamstring torque, especially at long muscle lengths (Lovell et al., 2016; Marshall et al., 2015), which persists for 45 minutes into the subsequent field-training session (Lovell et al., 2016). Since hamstring muscular fatigue is widely acknowledged as a HSI risk factor (Small et al., 2010), NHE $E_{\mathrm{BEF}}$ may exacerbate the risk in the subsequent session. Furthermore, our study has suggested that NHEBEF may compromise program adherence in community-level football. Whilst scheduling NHE $\mathrm{BEF}_{\mathrm{B}}$ is feasible for professional players, it is likely to compromise program adherence in amateur cohorts without supervision. Accordingly, scheduling of injury prevention exercises such as the NHE may be informed by a myriad of factors, including the standard of participation, the desired architectural adaptation (NHEBEF: fascicle length; NHEAFT: hypertrophy), the stage of the season, and the intended typology and load of the concomitant football training.

We accept that the modest compliance to the NHE interventions somewhat limits the conclusions that can be drawn, particularly regarding the diverse architectural responses. However, we traded the potential mechanistic insights of NHE scheduling for the ecological validity of administering the injury prevention program in a community setting. The use of 2D ultrasonography to observe changes in muscle architecture, particularly in an isolated segment of one muscle, is unlikely representative of the multitude of training adaptations incurred in the agonist and antagonist muscles engaged in knee flexion. In addition, the constrained field of view in the ultrasound transducer did not enable the direct measurement of muscle fascicle length. The field-based nature of this study also did not allow us to confirm our speculations regarding the role of NHE scheduling upon the signaling responses that mediate architectural adaptations, and that we are unable to discern whether changes in fascicle length are due to sarcomerogenesis or altered properties of the tendon. Finally, the typology and load of training undertaken both within and beyond the amateur football setting was not recorded during this study, and may influence the outcomes reported, however we attempted to negate this by randomizing within the three squads that participated in the study. 
In summary, modest compliance to a commonly adopted hamstring eccentric strengthening program in amateur football players resulted in moderate gains, irrespective of whether the program was administered before or after biweekly training sessions. However, the architectural adaptations that underpin strength gains differed according to scheduling. Given the range of factors that influence the optimal scheduling of injury prevention exercises, such as fatigue and program compliance, it may be advisable for injury prevention stakeholders to adopt a plastic approach to program scheduling, which may be influenced by the desired architectural adaptation, the planned training load for the football training session, or moreover the factors that govern program uptake and engagement.

\section{Perspective}

Engaging in a program of Nordic Hamstring Exercises has been effective in reducing the incidence of hamstring strain injuries (Arnason et al., 2008; Mjølsnes et al., 2004; Petersen et al., 2011), however recent research has demonstrated their fatiguing nature (Lovell et al., 2016; Marshall et al., 2015), which may acutely exacerbate the risk of injury when performed prior to training. This study has demonstrated that scheduling Nordic hamstring exercises before or after football training has similar eccentric strengthening outcomes, but divergent architectural adaptations. Considering the array of factors that influence both the adaptations and outcomes to injury prevention programs, together with the interaction of injury risk factors, careful consideration of exercise scheduling is necessary to optimize their efficacy. Our findings may have particular relevance to global injury prevention programs such as the FIFA11+ for Football, which is administered in the warm-up before training, but may be less pragmatic in community settings where injury prevention program compliance is a common challenge.

\section{Acknowledgements}

The authors would like to thank Matthew Stewart for his assistance with data collection, and to the players and coaches for their participation in the study. This work was funded by the New South Wales Sports Research and Injury Prevention Scheme.

\section{References}

1. Arnason A, Andersen TE, Holme I, Engebretsen L, Bahr R. Prevention of hamstring strains in elite soccer: an intervention study. Scand J Med Sci Sports 2008: 18: 40-48.

2. Bahr R, Thorborg K, Ekstrand J. Evidence-based hamstring injury prevention is not adopted by the majority of Champions League or Norwegian Premier League football teams: the Nordic Hamstring survey. Br J Sports Med 2015: 49: 1466-1471.

3. Batterham AM, Hopkins WG. Making meaningful inferences about magnitudes. Int J Sports Physiol Perform 2006: 1: 50-57.

4. Bizzini M, Junge A, Dvorak J. Implementation of the FIFA 11+ football warm up program: how to approach and convince the Football associations to invest in prevention. Br J Sports Med 2013: 47: 803- 
806.

5. Blazevich AJ, Cannavan D, Coleman DR, Horne S. Influence of concentric and eccentric resistance training on architectural adaptation in human quadriceps muscles. J Appl Physiol 2007: 103: 1565-1575.

6. Bourne MN, Duhig SJ, Timmins RG, Williams MD, Opar DA, Najjar AI A, Kerr GK, Shield AJ. Impact of the Nordic hamstring and hip extension exercises on hamstring architecture and morphology: implications for injury prevention. Br J Sports Med: Published Online First: 22 September 2016. doi:10.1136/bjsports-2016-096130.

7. Brockett CL, Morgan DL, Proske U. Human hamstring muscles adapt to eccentric exercise by changing optimum length. Med Sci Sports Exerc 2001: 33: 783-790.

8. Brughelli M, Mendiguchia J, Nosaka K. Effects of eccentric exercise on optimum length of the knee flexors and extensors during the preseason in professional soccer players Phys Ther Sport 2010: 11:50-55.

9. Clark R, Bryant A, Culgan J, Hartley B. The effects of eccentric hamstring strength training on dynamic jumping performance and isokinetic strength parameters: a pilot study on the implications for the prevention of hamstring injuries. Phys Ther Sport 2005: 6: 67-73.

10. Creer A, Gallagher P, Slivka D, Jemiolo B, Fink W, Trappe S. Influence of muscle glycogen availability on ERK1/2 and Akt signaling after resistance exercise in human skeletal muscle. J Appl Physiol 2005: 99: 950-956.

11. Douglas J, Pearson S, Ross A, McGuigan M. Chronic Adaptations to Eccentric Training: A Systematic Review. Sports Med 2016: Published Online First: 19 September 2016. doi:10.1007/s40279-016-0628-4.

12. Ekstrand J, Hagglund M, Walden M. Injury incidence and injury patterns in professional football: the UEFA injury study. Br J Sports Med 2011: 45: 553-558.

13. Ekstrand J, Waldén M, Hägglund $M$. Hamstring injuries have increased by $4 \%$ annually in men's professional football, since 2001: a 13-year longitudinal analysis of the UEFA Elite Club injury study. Br J Sports Med 2016: 50: 731-737.

14. Ekstrom RA, Donatelli RA, Carp KC. Electromyographic analysis of core trunk, hip, and thigh muscles during 9 rehabilitation exercises. J Orthop Sports Phys Ther 2007: 37: 754-762.

15. Franchi MV, Atherton PJ, Reeves ND, Flück M, Williams J, Mitchell WK, Selby A, Beltran Valls RM, Narici MV. Architectural, functional and molecular responses to concentric and eccentric loading in human skeletal muscle. Acta Physiol 2014: 210: 642-654.

16. Fyfe JJ, Bishop DJ, Zacharewicz E, Russell AP, Stepto NK. Concurrent exercise incorporating high-intensity interval or continuous training modulates mTORC1 signaling and microRNA expression in human skeletal muscle. Am J Physiol Regul Integr Comp Physiol 2016: 310: R1297-1311.

17. Gabbe BJ, Branson R, Bennell KL. A pilot randomised controlled trial of eccentric exercise to prevent hamstring injuries in community-level Australian Football. J Sci Med Sport 2006: 9: 103-109.

18. Guex K, Millet GP. Conceptual framework for strengthening exercises to prevent hamstring strains. Sports Med 2013: 43: 1207-1215. 
19. Hawkins RD, Hulse MA, Wilkinson C, Hodson A, Gibson M. The association football medical research programme: an audit of injuries in professional football. Br J Sports Med 2001: 35: 43-47.

20. Higbie EJ, Cureton KJ, Warren GL, Prior BM. Effects of concentric and eccentric training on muscle strength, cross-sectional area, and neural activation. J Appl Physiol 1996: 81: 2173-2181.

21. Hopkins WG. A spreadsheet for deriving a confidence interval, mechanistic inference and clinical inference from a $p$ value.

Sportscience 2007: 11:16-20. www.sportsci.org/2007/wghinf.htm (accessed $3^{\text {rd }}$ October 2016).

22. Iga J, Fruer C, Deighan M, Croix MD, James DV. 'Nordic' Hamstrings Exercise - Engagement Characteristics and Training Responses. Int $\mathrm{J}$ Sports Med 2012: 33: 1000-1004.

23. Junge $A$, Lamprecht $M$, Stamm $H$, Hasler $H$, Bizzini $M$, Tschopp $M$, Reuter H, Wyss H, Chilvers C, Dvorak J. Countrywide campaign to prevent soccer injuries in Swiss amateur players. Am J Sports Med 2011: 39: 57-63.

24. Kellis E, Galanis N, Natsis K, Kapetanos G. Validity of architectural properties of the hamstring muscles: correlation of ultrasound findings with cadaveric dissection. J Biomech 2009: 42: 2549-2554.

25. Krustrup P, Mohr M, Steensberg A, Bencke J, Kjaer M, Bangsbo J. Muscle and blood metabolites during a soccer game: implications for sprint performance. Med Sci Sports Exerc 2006: 38: 1165-1174.

26. Lovell R, Siegler JC, Knox M, Brennan S, Marshall PWM. Acute neuromuscular and performance responses to Nordic hamstring exercises completed before or after football training. J Sports Sci 2016: 34: 2286-2294.

27. Lundberg TR, Fernandez-Gonzalo R, Gustafsson T, Tesch PA. Aerobic exercise does not compromise muscle hypertrophy response to shortterm resistance training. J Appl Physiol 2013: 114: 81-89.

28. Magalhães J, Rebelo A, Oliveira E, Silva JR, Marques F, Ascensão A. Impact of Loughborough Intermittent Shuttle Test versus soccer match on physiological, biochemical and neuromuscular parameters. Eur J Appl Physiol 2010: 108: 39-48.

29. Marshall PWM, Lovell R, Jeppesen GK, Andersen K, Siegler JC. Hamstring muscle fatigue and central motor output during a simulated soccer match. PLoS ONE 2014: 9: e102753.

30. Marshall PWM, Lovell R, Knox MF, Brennan SL, Siegler JC. Hamstring Fatigue and Muscle Activation Changes During Six Sets of Nordic Hamstring Exercise in Amateur Soccer Players. J Strength Cond Res 2015: 29: 3124-3133.

31. McCall A, Carling C, Nédélec M, Davison M, Le Gall F, Berthoin S, Dupont $G$. Risk factors, testing and preventative strategies for noncontact injuries in professional football: current perceptions and practices of 44 teams from various premier leagues. Br J Sports Med 2014: 48: 1352-1357.

32. Mjølsnes R, Arnason A, Østhagen T, Raastad T, Bahr R. A 10-week randomized trial comparing eccentric vs. concentric hamstring strength training in well-trained soccer players. Scand J Med Sci Sports 2004: 14: 311-317. 
33. Morgan DL. New insights into the behavior of muscle during active lengthening. Biophys J 1990: 57: 209-221.

34. Opar DA, Williams MD, Timmins RG, Hickey J, Duhig SJ, Shield AJ. Eccentric hamstring strength and hamstring injury risk in Australian footballers. Med Sci Sports Exerc 2015: 47: 857-865.

35. Petersen J, Thorborg K, Nielsen MB, Budtz-Jørgensen E, Hölmich P. Preventive effect of eccentric training on acute hamstring injuries in men's soccer: a cluster-randomized controlled trial. Am J Sports Med 2011: 39: 2296-2303.

36. Rainoldi A, Melchiorri G, Caruso I. A method for positioning electrodes during surface EMG recordings in lower limb muscles. J Neurosci Methods 2004: 134: 37-43.

37. Small K, Mcnaughton L, Greig M, Lovell R. Effect of timing of eccentric hamstring strengthening exercises during soccer training: implications for muscle fatigability. J Strength Cond Res 2009: 23: 1077-1083.

38. Sole G, Milosavljevic S, Nicholson HD, Sullivan SJ. Selective strength loss and decreased muscle activity in hamstring injury. $J$ Orthop Sports Phys Ther 2011: 41: 354-363.

39. Timmins RG, Bourne MN, Shield AJ, Williams MD, Lorenzen C, Opar DA. Short biceps femoris fascicles and eccentric knee flexor weakness increase the risk of hamstring injury in elite football (soccer): a prospective cohort study. Br J Sports Med 2016: 50:1524-1535.

40. Timmins RG, Ruddy JD, Presland J, Maniar N, Shield AJ, Williams MD, Opar DA. Architectural Changes of the Biceps Femoris After Concentric or Eccentric Training. Med Sci Sports Exerc 2016: 48: 499508.

41. Timmins RG, Shield AJ, Williams MD, Lorenzen C, Opar DA. Biceps femoris long head architecture: a reliability and retrospective injury study. Med Sci Sports Exerc 2015: 47: 905-913.

42. van Beijsterveldt AMC, Stubbe JH, Schmikli SL, van de Port IGL, Backx FJG. Differences in injury risk and characteristics between Dutch amateur and professional soccer players. J Sci Med Sport 2015: 18: 145-149.

43. van der Horst N, Smits DW, Petersen J, Goedhart EA, Backx FJG. The Preventive Effect of the Nordic Hamstring Exercise on Hamstring Injuries in Amateur Soccer Players: A Randomized Controlled Trial. Am J Sports Med 2015: 43:1316-1323. 